\title{
الحساسية الانفعالية لدى المعاقين سمعيًا بكلية الخليج في سلطنة عُمان
}

\author{
ثريا بنت راشد بن عبدالله القرطوبية \\ ماجستير في الإرشاد والتوجيه- كلية العلوم والآداب- جامعة نزوى- سلطنة عُمان القرطوبئ \\ أحمد محمد جلال الفواعير

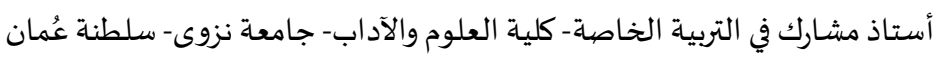 \\ fawair@unizwa.edu.om
}

هدفت هذه الدراسة تعرف مستوى الحساسية الانفعالية لدى المعاقين سمعيا بكلية الخليج في سلطنة عمان، واتبعت الدراسة المنهج

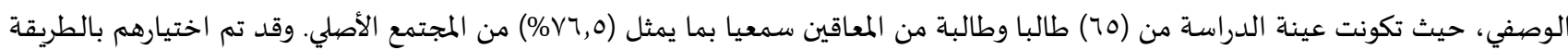

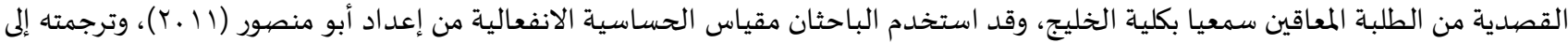

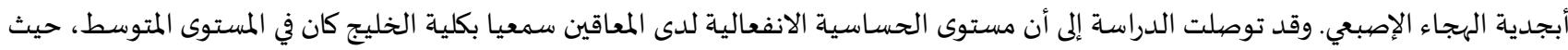

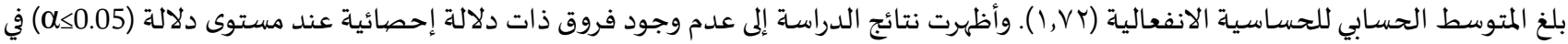

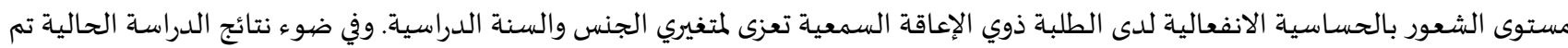
تقديم مجموعة من التوصيات.

الكلمات المفتاحية: الحساسية الانفعالية، المعاق سمعيا، كلية الخليج. (ब) (1)

المقدمة:

للانفعال قوة دافعة تدفع الكائن الحي إلى التنوع في السلوك الصادر عنه إلى أن يحقق هدفه من الانفعال، ويقلل من حدة التوتر الذي يسببه

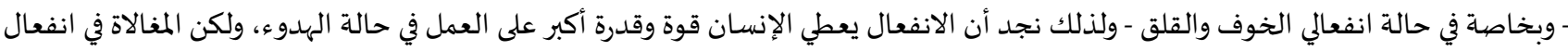

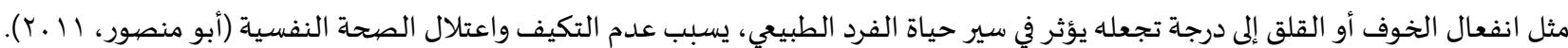

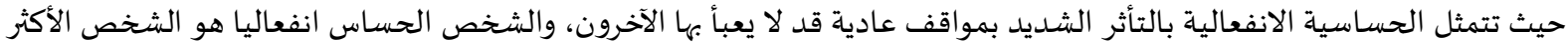

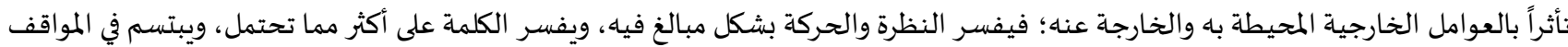

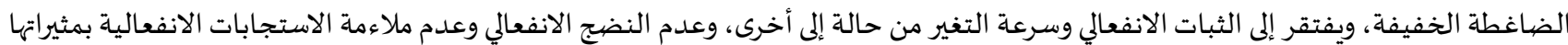

(Wallbott \& Seithe, 1993)

والفقدان الحسي لذوي الإعاقة السمعية يحرههم من بعض المصادر المادية التي من خلالها يتم تكوين وبناء شخصيتهم ودينامياتها وسماتها؛

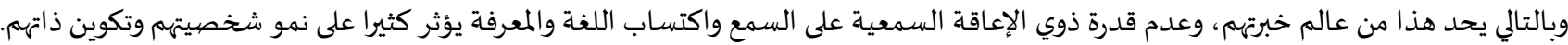

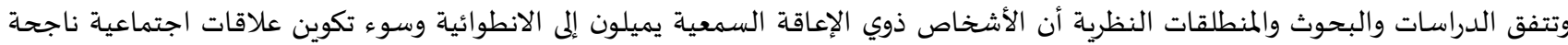
وفاعلة مع الآخرين، ويكون مستوى النضج الاجتماعي منخفض، وضعف القدات والقدرة على اكتساب المهارات الاستقلالية بالتالي انخفاض السلوك التكيفي

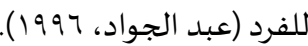

وتوجد الحساسية الانفعالية لدى جميع أفراد المجتمع بشكل عام، وقد تكون الحساسية الانفعالية لدى البعض الآخر بشكل مبالغ فيها. حيث يتأثر الشخص الحساس انفعالياً بسرعة لأتفه الأسباب قد تكون غير منطقية، ولا يتقبل النقد، ويفسر كلام ونظرات الآخربن أكثر مما يحتمل. وبالتالي يتولد لدياه مشاعر اليأس والإحباط.

وقد لا يجد الطلبة ذوي الإعاقة السمعية لتأثرهم بما يتعرضون لله بالمواقف العادية في البيئة المحيطة بهم الإهتمام اللازم من الآخرون؛ مما يجعلهم ينفعلون لأتفه الأسباب، وتصدر عنهم ردود فعل عنيفة لا يستطيعون السيطرة علها. وقد تكون هذه الانفعالات مشابهة لانفعالات مرحلة الطفولة (أبومنصور، (1) . T). 
وقد عرف بهاتيا (Bhatia,2009) الحساسية الانفعالية بأنها التأثر الشديد والمبالغة بالمواقف العادية والأحداث التي يمر بها الشخص في

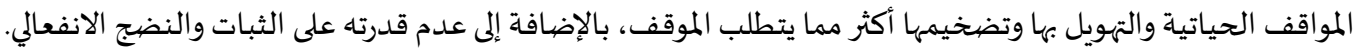

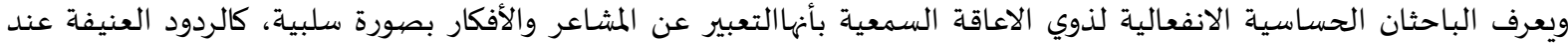

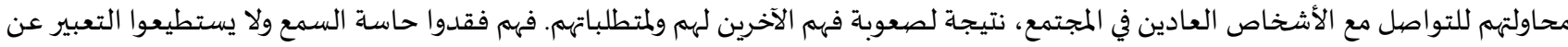

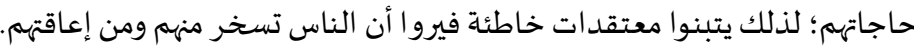

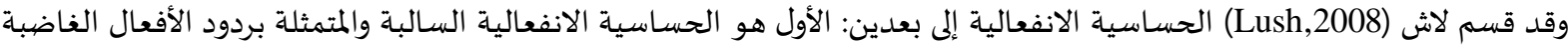

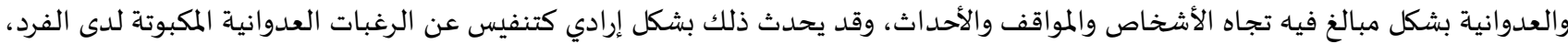

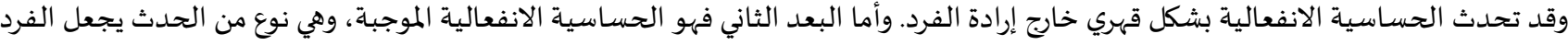

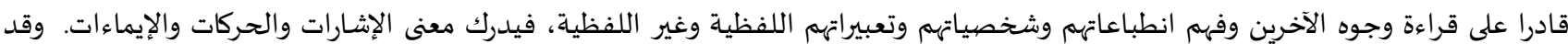

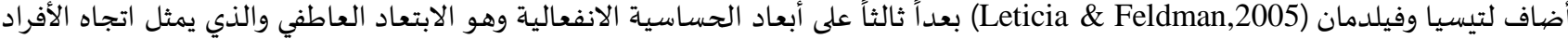

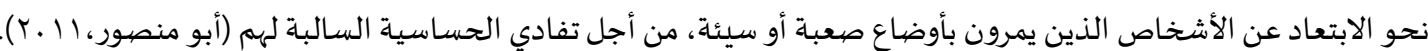

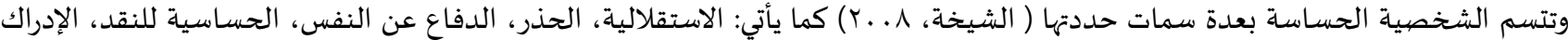
والوعي، وأخيراً الإخلاص.

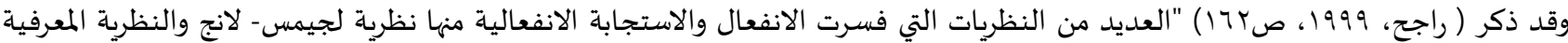
ونظرية كانون بارد كما يأتي:

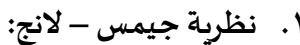

يرى أصحاب هذه النظرية أن التغيرات الفسيولوجية التي تطرأ على الفرد عندما يتعرض لمواقف أو الفئ مثيرات بيئية، هي المسؤولة عن انفعالاته.

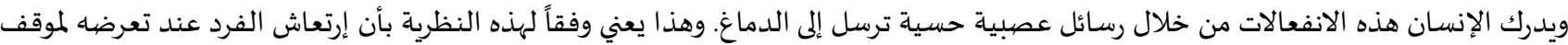
مخيف هو السبب في شعوره بالخوف. ومن هنا فإن هذه النظرية تفسر حدوث فرط الحساسية الانفعالية نتيجة الشعور بالاستجابات الفسيولوجية

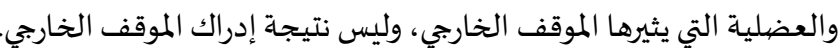

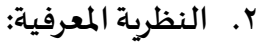

ويرى أصحاب النظرية المعرفية أن الحساسية الانفعالية تتكون من معلومات معقدة كثيرة تتضمن ما يلي: المعلومات المتعلقة بالأحداث البيئية التي تصل إلى النخاع المني عن طريق أعضاء الحس. الحس. المعلومات المخزنة في الدماغ التي يتم الاستعانة بها في تقدير وتفسير الأحداث الجديدة.

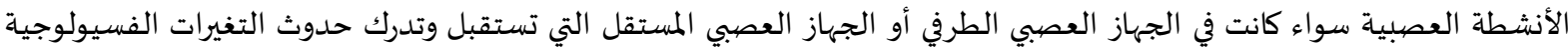

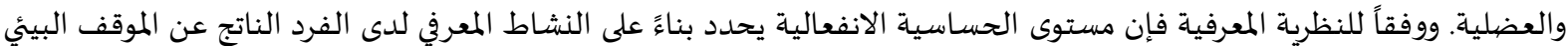
الذي تحدث فيه التغيرات الفسيولوجية والعضلية.

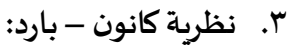

يرى أصحاب هذه النظرية أن الانفعال ينتج عن عدة أنماط من الأنشطة العصبية الناتجة عن مثيرات بيئية والتي تؤثر على الفرد كما يأتي: ترسل أنماط النشاط العصبي إلى الجهاز العصببي المستقل حيث تنبه التغيرات الفسيولوجية والعضلية لفرط الحساسية الانفعالية. ترسل أنماط النشاط العصبي أيضا - وفي نفس الوقت - إلى النخاع المخي حيث تسبب الإدراك. ويتضح بأن نظرية كانون - بارد ترى بأن التغيرات الفسيولوجية والعضلية ليس لها علاقة في إحداث الفياث فرط الحساسية الإنفعالية، وإنما

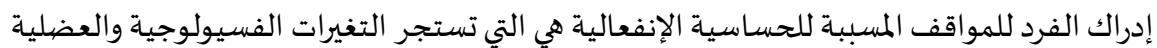

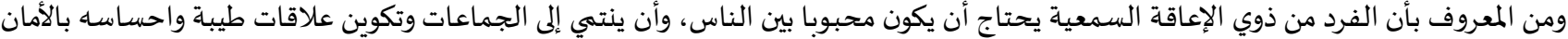

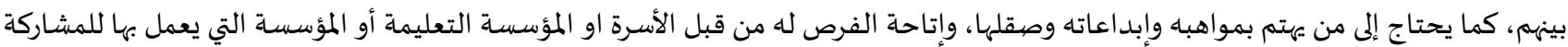

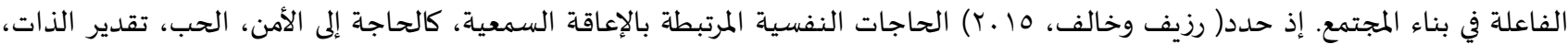

تحقيق الذات، والحاجة إلى الفهم والمعرفة. وقد أوضح ستيفنسون وآخرون (Stevenson, Kreppner, Pimperton, Worsfold, \& Kennedy, 2015) أن المعاق سمعيا يميل إلى الانطواء،

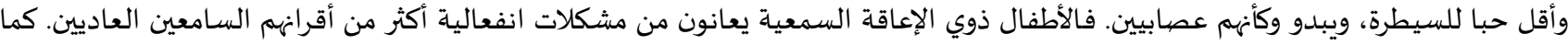

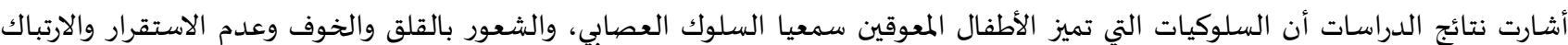

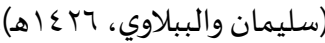


وأكد جريجوري (Gregory) أن الصم يميلون إلى العزلة والهروب من تحمل المسئولية، ويتسم الأصم بالاضطرابات النفسية والانفعالية.

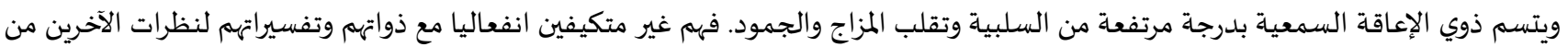

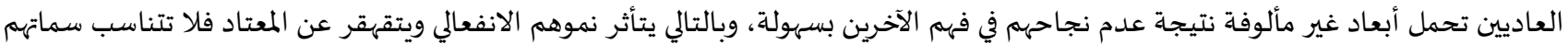

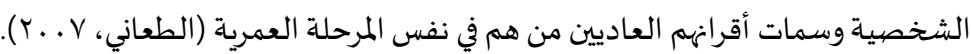

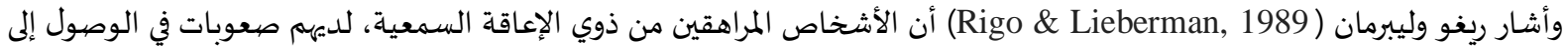

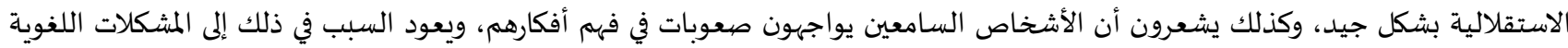

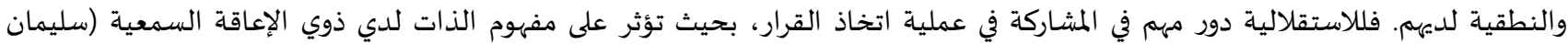
والببلاوي، بrع (هـ). والإعاقة السمعية تحد من قدرات وخبرات الأشخاص ذوي الإعاقة السمعية؛ حيث أهمم لا يمكن أن يتواصلوا مع كافة جوانب البيئة

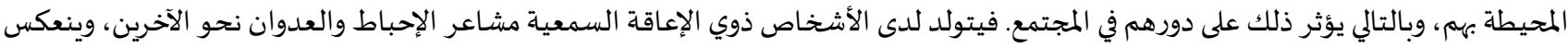

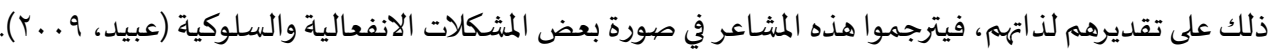

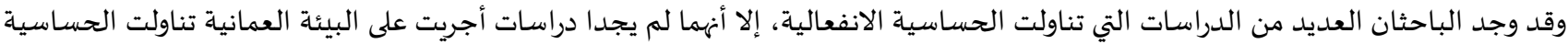
الإنفعالية لدى ذوي الإعاقة السمعية. فقد هدفت دراسة أبو شعيشع (1) ا ب) إلى معرفة العلاقة بين الحساسية الانفعالية والسلوك التوافقي والسلوك العدواني لدى المعاقين سمعيا، حيث

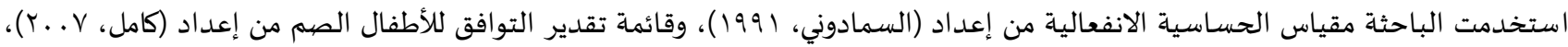

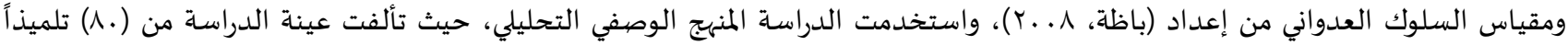

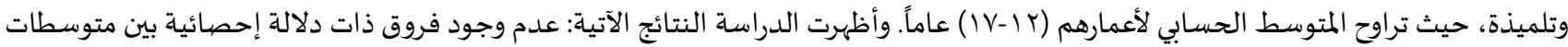

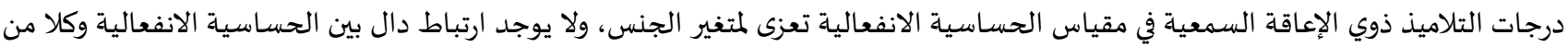
السلوك التوافقي والسلوك العدواني لدى المعاقين سمعيا.

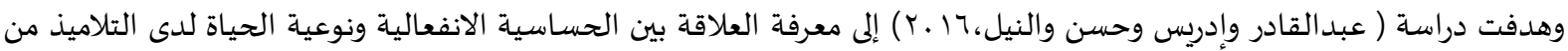

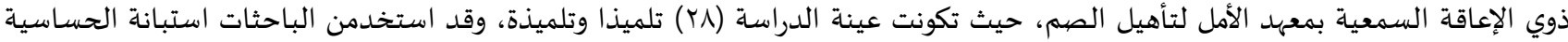

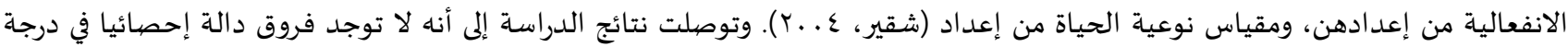

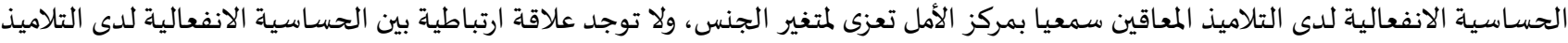
المعاقين سمعيا بمعهد الأمل ولاية الخرطوم ونوعية الحياة.

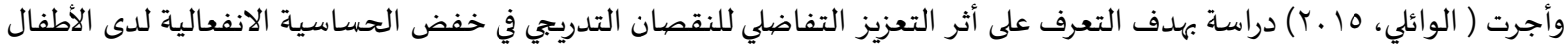

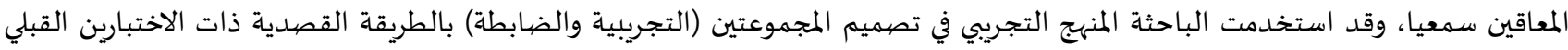

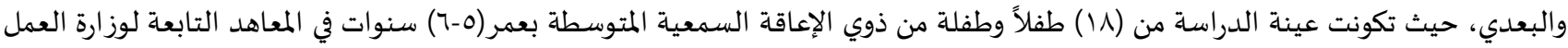

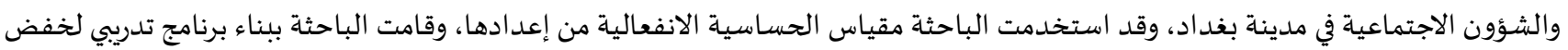

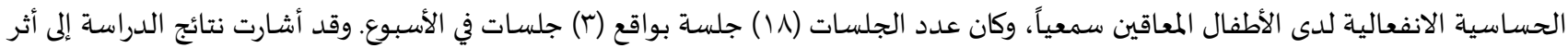

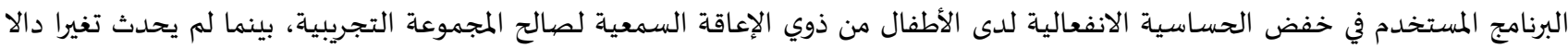

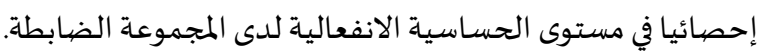

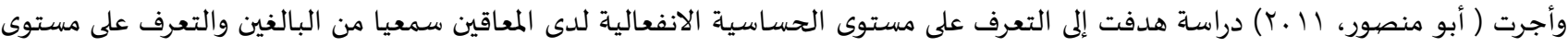

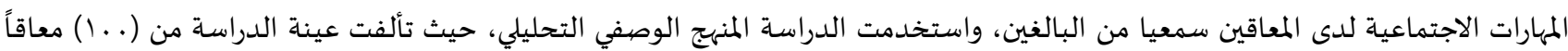

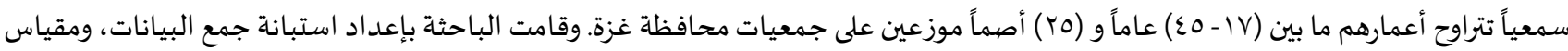

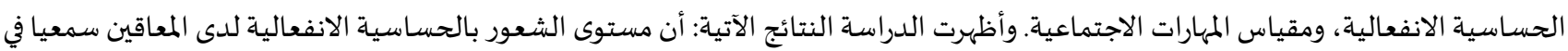

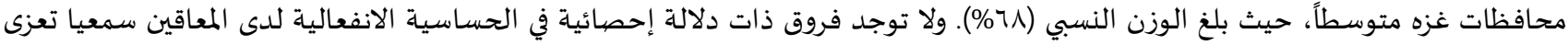

لمتغير الجنس، ولا توجد علاقة ارتباطية بين مستوى المهارات الاجتماعية لدى المعاقين سمعيا ومستوى الحساسية الانفعالية لدى المعاقيات الماتين سمعيا.

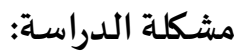
إن علاقة الطفل ذوي الإعاقة السمعية مع الآخرين مملوءة باتجاهات انفعالية متذبذبة، فيفضل الانسحاب والانعزال عنهم؛ لأن ذلك الأن الإنية

يشعره بالأمن، فوجود الآخرين بجانباه يسبب له القلق؛ لذلك فهو يعاني من القلق الاجتماعي والحساسية الانفعالية (الوائلي، 10 .ب). 


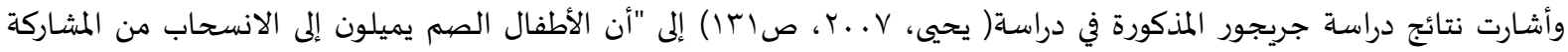

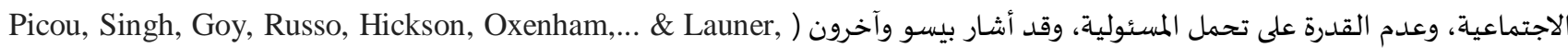

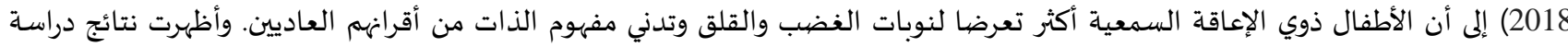
بريسمان وآخرون (Pressman, Pipp-Siegel, Yoshinaga-Itano, \& Deas, 1999) إلى وجود مشاعر النقص وسوء الإن التكيف الاجتماعي والأسري لدى الأطفال ذوي الإعاقة السمعية. وأن لفقدان حاسة السمع أثر كبير على السلوك الانفعالي للفرد، ويشكل عقبات أمام اندماجه في المجتمع المحيط باه. فالإعاقة السمعية

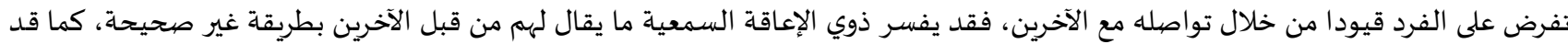

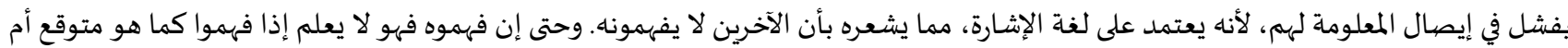

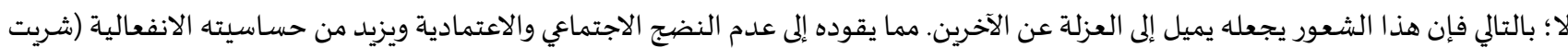

ومن خلال خبرة الباحثة الأولى في تدرس مساقات الإعاقة السمعية لدى الطلبة ذوي الإعاقة السمعية الذين هم في سن المراهقة أو الرشد

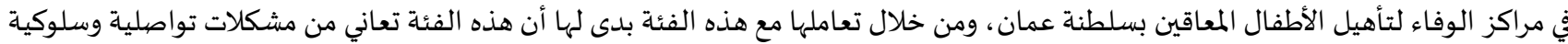

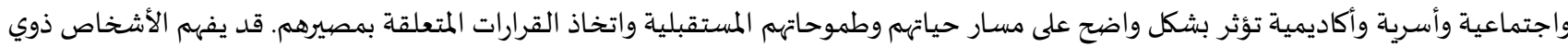

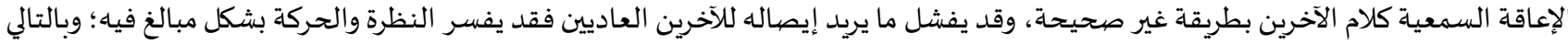

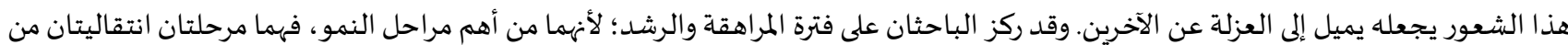

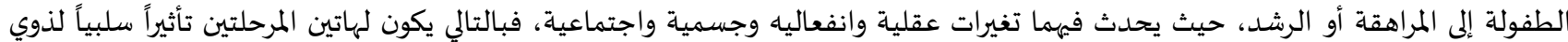

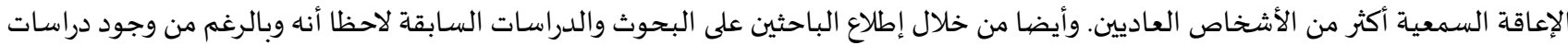

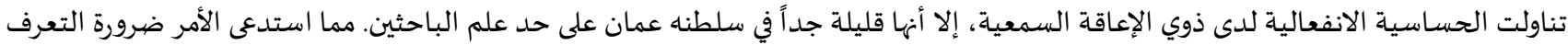
على مستوى الحساسية الانفعالية لدى ذوي الإعاقة السمعية في كلية الخليج.

أهداف الدراسة:

ا. التعرف على مستوى الحساسية الانفعالية لدى ذوي الإعاقة السمعية بكلية الخليج في سلطنة عمان. r. الكشف عن الفرق في الحساسية الانفعالية لدى ذوي الإعاقة السمعية بكلية الخليج في سلطنة عمان تعزى لمتغيري (الجنس، السنة الدراسية).

أسئلة الدراسة:

1. ما مستوى الحساسية الانفعالية لدى ذوي الإعاقة السمعية بكلية الخليج في سلطنة عمان؟

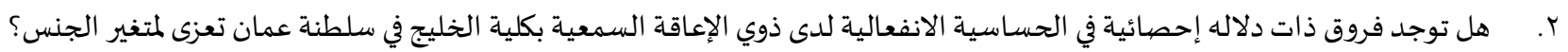
r. هل توجد فروق ذات دلاله إحصائية في الحساسية الانفعالية لدى ذوي الإعاقة السمعية بكلية الخليج في سلطنة عمان تعزى لمتغيرالسنة

الدراسية؟

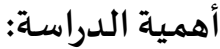
تبرز أهمية الدراسة نظرياً من أهمية الموضوع الذي تناولته، حيث ستثري هذه الدراسة الإطار النظري المتعلق بالإعاقة السمعية بشكل عام المام المارية

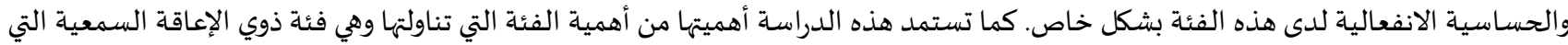

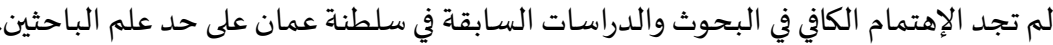
وأما من الناحية التطبيقية فقد قدمت الدراسة الحالية مقياساً مترجماً بلغة الإشارة (أبجدية الهجاء الإصبعي) يمكن الاستفادة منه

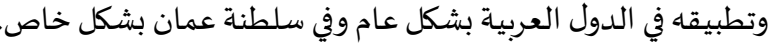

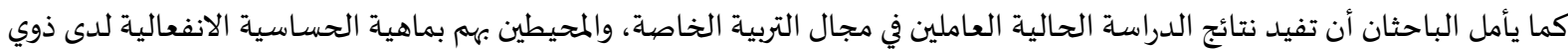


الحدود الموضوعية: الحساسية الانفعالية لدى ذوي الإعاقة السمعية بكلية الخليج في سلطنه عمان. الحدود البشرية: عينة مقصودة من ذوي الإعاقة السمعية بكلية الخليج (ذكور - إناث) في سلطنة عمان.

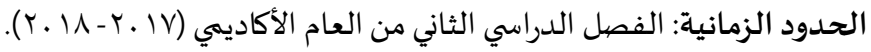
الحدود المكانية: كلية الخليج في سلطنة عمان. الحدود السيكومترية: وتتمثل بالمقياس المعد لهذه الدراسه وخصائصها السيكومترية (الصدق والثبات) واستجابات المفحوصين الموضوعية على فقرات المقياس.

\section{مصطلحات الدراسـة:}

تتضمن هذه الدراسة تعريفاً لمصيطلحات الدراسة النظرية والإجرائية الآتية:

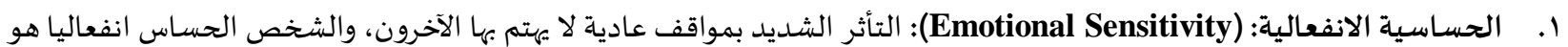

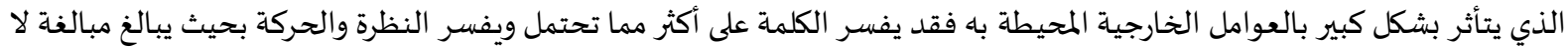

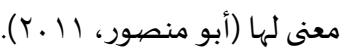
ويعرفها الباحثان اجرائياً بأهها الدرجة التي يحصورانيل عليها المفحوصون على مقياس الحساسية الانفعالية المستخدم في أغراض الدراسة الحالية. r. المعاق سمعيا: هو الشخص الذي يعاني من نقص أو تعويق لحاسـة السمع بصورة ملحوظة لدرجة أهها تمنع أو تعوق الوظيفة السمعية؛

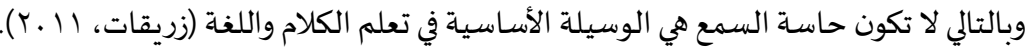
ويعرفه الباحثان اجرائياً: هم الطلبة الذين تم تشخيصهيم بأههم من ذوي الإعاقة السمعية سواء كانوا من فئة ضعاف السمع او الصهيم الملتحقون

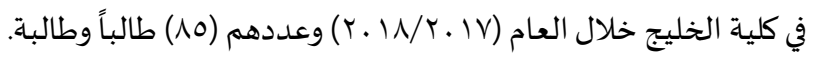

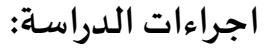

يعرض هذا الجزء منهج الدراسة ومجتمعها وعينتها ومتغيراتها وأدواتها.

$$
\text { منهج الدراسة : من }
$$

استخدم الباحثان المنهج الوصفي، لمناسبتها لطبيعة الدراسة كونها تسعى إلى وصف طبيعة البيانات المستمدة من أفراد عينة الدراسة في

ضوء بعض المتغيرات (الجنس، السنة الدراسية).

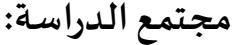

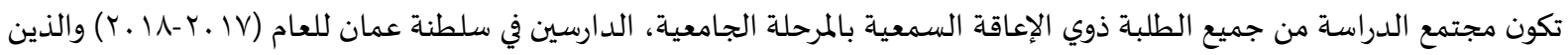
بلغ عددهم (م) طالباً وطالبة، من كلية الخليج بمحافظة مسقط، وذلك لأنها المؤسسة الجامعية الوحيدة في سلطنة عمان التي تضمر طلبة ذوي الإعاقة السمعية عندما أجريت هذه الدراسة على حد على علم الباحثين.

\begin{tabular}{|c|c|c|c|c|}
\hline \multirow[t]{2}{*}{ النسبة المئوية } & \multirow[t]{2}{*}{ الإجمالي } & \multicolumn{2}{|c|}{ الجنس } & \multirow[t]{2}{*}{ السنة الدراسية } \\
\hline & & ذكور & إناث & \\
\hline$\%$ \%. & IV & ir & 0 & السنة التأسيسية \\
\hline \%rr & 19 & 11 & $\wedge$ & السنة الثانية \\
\hline$\%$ \%. & IV & 11 & 7 & السنة الثالثة \\
\hline$\% r r$ & TV & 19 & $\wedge$ & السنة الرابعة \\
\hline$\% 7$ & 0 & $r$ & $r$ & السنة الخامسة \\
\hline \multirow[t]{2}{*}{$\% 1 \ldots$} & 10 & 00 & $r$. & الإجمالي \\
\hline & $\% 1$. & $\% 70$ & \%ro & النسبة المئوية \\
\hline
\end{tabular}

جدول (1): إحصائية بأعداد الطلبة المعاقين سمعيا المنتظمين في كلية الخليج

عينة الدراسـة: طبق الباحثان أداة الدراسة على عينة استطلاعية أولية قوامها (V) طالبات من إحدى مدارس الدمج في محافظة الباطنة، بهدف التأكد من مدى فهم الطالبات من ذوي الإعاقة السمعية لفقرات المقياس. 
ثم اختار الباحثان عينة استطلاعية أخرى قوامها (.ب) طالباً وطالبة، من مجتمع الدراسة الأصلي، وتم تطبيق أداة الدراسة على هذه العينة بهدف

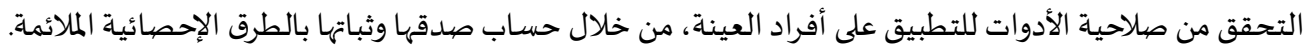

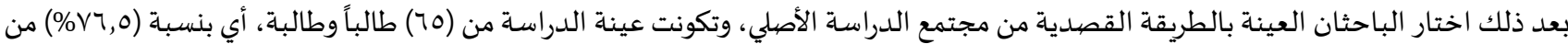
مجتمع الدراسـة.

جدول (r): توزيع العينة حسب المتغيرات (الجنس، السنة الدراسة)

\begin{tabular}{|c|c|c|c|c|c|c|c|}
\hline \multirow[t]{2}{*}{ النسبة المئوية } & \multirow[t]{2}{*}{ الإجمالي } & \multicolumn{5}{|c|}{ السنة الدراسة } & \multirow[t]{2}{*}{ الجنس } \\
\hline & & الخامسة & الرابعة & الثالثة & الثانية & الأولى & \\
\hline$\% 77$ & $\varepsilon r$ & r & v & 11 & 11 & ir & ذكر \\
\hline$\% ऍ \varepsilon$ & r & $r$ & r & 7 & 1 & 0 & أنثى \\
\hline$\% \curlywedge \ldots$ & 70 & 0 & 9 & IV & IV & IV & المجموع \\
\hline & $\% 1$. & $\% \wedge$ & $\% 1 \varepsilon$ & $\%$ \% & $\%$ \% & $\%$ Y & النسبة المئوية \\
\hline
\end{tabular}

أداة الدراسـة:

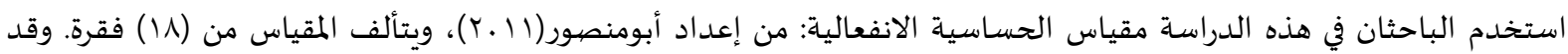

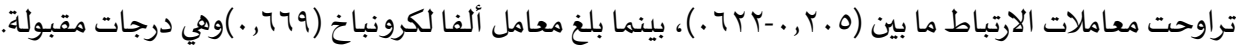
فيما بعد قام الباحثان بإعادة صياغة فقرات مقياس الحساسية الانفعالية بما يتناسب مع المراهقين والراشدين لذوي الإعاقة السمعية. وللتحقق من

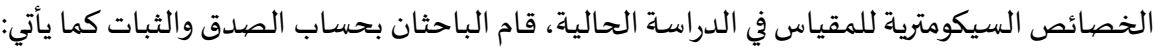
قام الباحثان بحساب صدق المقياس بطريقتين وهما: طريقة الصدق الظاهري، وصديدق المفردات.

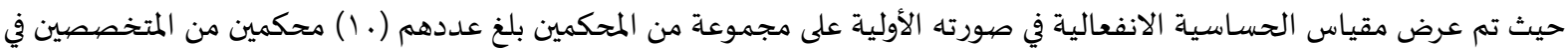
الإشاد النفسي، وعلم النفس، والقياس والتقويم، والتربية الخاصة، وتربية الطفل من حملة درجة الدكتوراة والماجستير في كل من جامعة نزوى

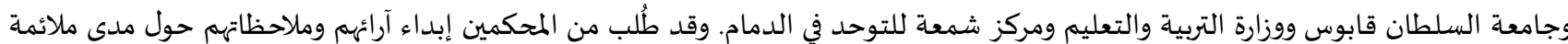
فقرات المقياس لغرض الدراسة، ودرجة انتماء الفقرات لله، ومدى وضوح الصياغة اللغوية لكل فقرة من فقرات المقياس، كذلك ملاحظاتهم

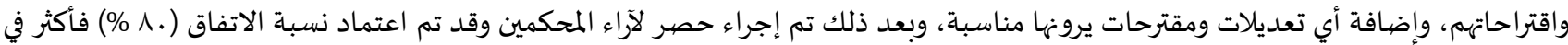
رآراء أعضاء التحكيم. وقام الباحثان بتعديل وإعادة صياغة فقرة واحدة رقم (V) التي رأى أعضاء التحكيم تعديلها لعدم وضوحها أو احتمالها أكثر من

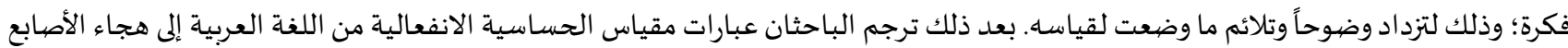
الإشاري ليتناسب مع أفراد العينة. ولحساب صدق المفردات قام الباحثان بحساب معامل ارتباط بيرسون (Pearson Correlation Coefficient) لفقرات المقياس مع الدرجة

الكلية لمقياس الحساسية الانفعالية.

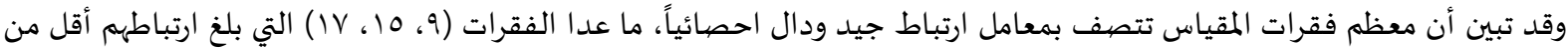

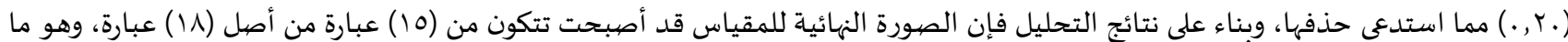
اعتمده الباحثان في هذه الدراسة. وأما ثبات أداة الدراسة فده فـد قام الباحثان بحساب معامل الثبات الكلي لمقياس الحساسية الانفعالية باستخدام معامل ألفا لكرو نباخ

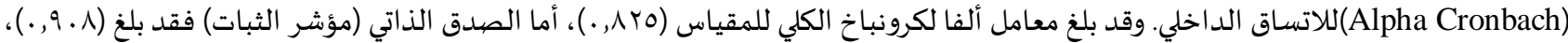
وهو معامل ثبات جيد ومناسب لأهداف الدراسة.

عرض نتائج الدراسة وتفسيرها: يتناول هذا الجزء نتائج الدراسة وتفسيرها كما يأتي: أولاً: عرض النتائج المتعلقة بالسؤال الأول: والذي نص ندائ على الآتي: ما مستوى الحساسية الانفعالية لدى طلبة ذوي الإعاقة السمعية في كلية الخليج؟ من أجل الإجابة على هذا السؤال تم حساب المتوسطات الحسابية والانحرافات المعيارية ومستوى الحساسية الانفعالية لفقرات المقياس

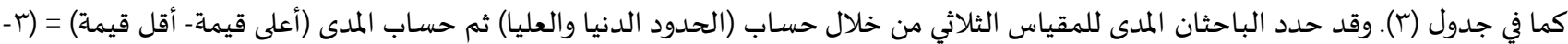

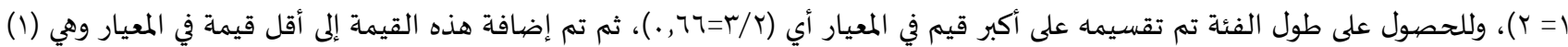


لتحديد الحد الأعلى لهذه الفئة. وبناء عللى ذلك تعبر المتوسطات الحسابية (. . - ـ 1,77) عن مستوى حساسية انفعالية منخفض، والمتوسطات

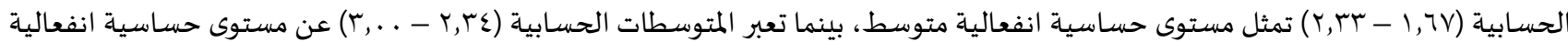

يظهر في جدول(r) المتوسطات الحسابية والانحرافات المعيارية والتكرارات والنسب المئوية ومستوى الحساسية الانفعالية والدرجة الكلية لمقياس

الحساسية الانفعالية.

جدول (r): المتوسطات الحسابية والانحر افات المعيارية والتكرارات والنسب المئوية ومستوى الحساسية الانفعالية

\begin{tabular}{|c|c|c|c|c|c|c|}
\hline مستوى الحساسية الانفعالية & الانحراف المعياري & المتوسط الحسابي & النسبة & التكرار & مستوى الحساسية الانفعالية & المقياس \\
\hline \multirow[t]{3}{*}{ متوسط } & \multirow[t]{3}{*}{, ro } & \multirow[t]{3}{*}{ I,VT } & $\% \nmid \cdot, \wedge$ & $v$ & منخفض & \multirow{3}{*}{ الحساسية الانفعالية الكلية لمقياس } \\
\hline & & & $\% \wedge \wedge, \vee$ & or & متوسط & \\
\hline & & & $\% 1,0$ & 1 & مرتفع & \\
\hline
\end{tabular}

يتضح من جدول (r) أن مستوى الحساسية الانفعالية كان في المستوى المتوسط بمتوسط حسابي بلغت قيمته (Y) (I, وبانحراف معياري

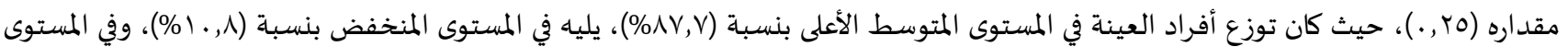

المرتفع بنسبة (1,0) ويوضح جدول (ع) المتوسطات الحسابية والانحرافات المعيارية ومستوى الحساسية الانفعالية وترتيب الفقرات.

جدول (ع): المتوسطات الحسابية والانحر افات المعيارية ومستوى الحساسية الانفعالية لفقرات مقياس الحساسية الإنفعالية

\begin{tabular}{|c|c|c|c|c|c|}
\hline الترتيب & مستوى الحساسية & الانحراف المعياري & المتوسط الحسابي & 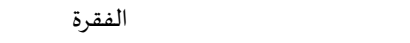 & رقم الفقرة \\
\hline 1 & منخفض &., 07 & $1, \varepsilon 0$ & أسيئ الظن بالآخرين. & 1 \\
\hline r & منخفض &., 07 & 1,00 & أنفعل لردود فعل الآخرين بسرعة. & r \\
\hline$\varepsilon$ & منخفض &., 79 & 1,70 & يصعب علي ضبط انفعالاتي. & $r$ \\
\hline 1. & متوسط & $\cdot, \mathrm{VV}$ & 1, Vo & أحب العزلة والانطواء على الذات. & $\varepsilon$ \\
\hline ० & منخفض & $\cdot, V \varepsilon$ & 1,77 & أتضايق من نقد الآخرين لي. & ० \\
\hline ir & متوسط & $\cdot, \mathrm{VA}$ & $1, \wedge$ & أتحمل أن يكرهني أحد. & 7 \\
\hline 7 & منخفض & $\cdot, \mathrm{TV}$ & 1,77 & أهتم بالتفاصيل البسيطة وأضخمها & $v$ \\
\hline$r$ & منخفض &., 77 & 1,01 & أشعر بالإهانة والألم الشديد لو تجاهلني أحد. & $\wedge$ \\
\hline $1 \varepsilon$ & متوسط & $\cdot, \mathrm{TV}$ & 1,91 & أشعر بأن الناس تتعمد مضايقتي. & 9 \\
\hline 9 & متوسط & $\cdot, \mathrm{VT}$ & $1, v 1$ & أفسر الموقف أكثر مما يحتمل. & 1. \\
\hline v & متوسط & $\cdot, 77$ & 1,79 & أحاول أن أظهر بصورة أفضل من الآخرين. & 11 \\
\hline 10 & متوسط & $\cdot, \mathrm{Vq}$ & $r, . r$ & أشعر بالحرج من التواصل أمام الآخرين. & ir \\
\hline$\wedge$ & متوسط & $\cdot, 77$ & 1,79 & أشعر بالضيق من عدم احترام الآخرين لي. & ir \\
\hline 11 & متوسط & $\cdot$, Vo & $1, \mathrm{VV}$ & أتجنب الوقوع في أي خطأ لو كان بسيطا. & $1 \varepsilon$ \\
\hline ir & متوسط & $\cdot, \mathrm{VI}$ & 1,10 & أفسر أقوال أو أفعال الآخرين بصورة خاطئة. & 10 \\
\hline
\end{tabular}

ويتضح من جدول (ع) أن أعلى مستوى للحساسية الإنفعالية كان في الفقرات (10، 10،9)، بينما كان أدنى مستوى للحساسية الإنفعالية في

الفقرات (I.Y.人).

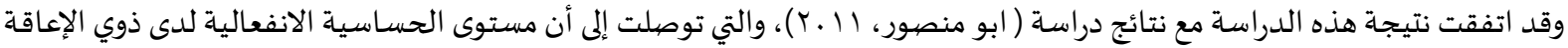

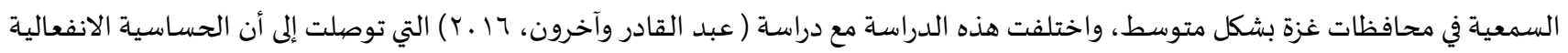
لدى التلاميذ ذوي الإعاقة السمعية في المرحلة الثانوية بمعهد الأمل بولاية الخرطوم بدرجة فئدة فوق المتوسط. ويعزو الباحثان أسباب ظهور الحساسية الانفعالية بشكل متوسط لدى طلبة ذوي الإهائ الإعاقة السمعية في كلية الخليج إلى تقديم البرامج الإرشادية والنفسية لهم داخل الكلية، أو في المؤسسات التعليمية التي كان يتلقى فيها التعليم سابقا. وقد يعود إلى تقديم البرامج التوعوية والمحاضرات

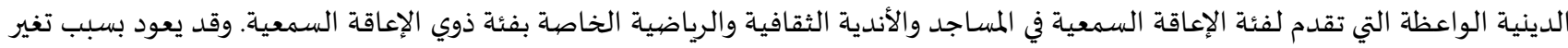

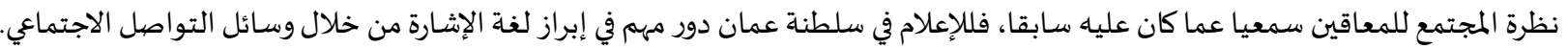
وهذا يتوافق على ما أكدته دراسة شريت ومحمد (0 . ب) بأن مشاركة ذوي الإعاقة السمعية في الأنشطة المختلفة تساعدهم على فهم البيئة المحيطة بهم وتطور سلوكهم الاجتماعي، ويمكنهم السيطرة على انفعالاتهم، ويعبروا عنها بشكل مناسب حيث يؤثر ذلك بشكل واضح على شخصياتهم. 
وقد أشار بعض الباحثين أن ذوي الإعاقة السمعية كلما كانت لديهم القدرة على تكوين صداقات اجتماعيه مع أقرانهم والمشاركة في البرامج

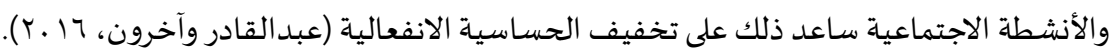
ثانياً: عرض النتائج المتعلقة بالسؤال الثاني الذي نص على الآتي: هل توجد فروق ذاعدات دالئل الآلة إحصائية في مستوى الحساسية الانفعالية تعزى

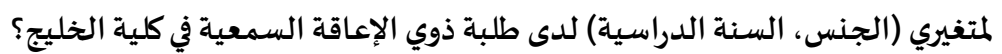

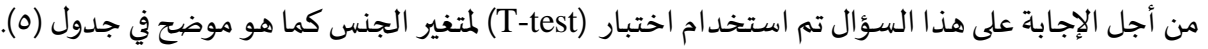

\begin{tabular}{|c|c|c|c|c|c|c|c|c|}
\hline اتجاه الدلالة & مستوى الدلالة & قيمة ت & درجات & المعياري & المتوسطي & العدد العد & الجنس & الحساسية الانفعالية \\
\hline \multirow[t]{2}{*}{ غير دالة إحصائياً } & \multirow[t]{2}{*}{ דו } & \multirow[t]{2}{*}{., $9 \pi r$} & \multirow[t]{2}{*}{$4 \pi$} &.,$Y$ I & $1, v \varepsilon$ & $\varepsilon r$ & ذكور & \multirow[t]{2}{*}{ الدرجة الكلية } \\
\hline & & & & T & 1,71 & Kr & إناث & \\
\hline
\end{tabular}

$\alpha \leq 0.05$ د دالة عند مستوى * يتضح من جدول (0) لاختبار "ت" (T-test) عدم وجود فروق ذات دلالة إحصائية عند مستوى دلالة (150.05) بين الذكور (المتوسط الحسابي =

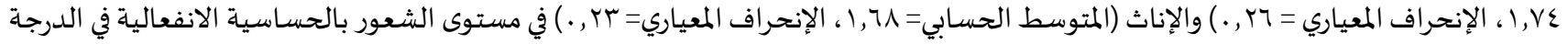
الكلية للمقياس.

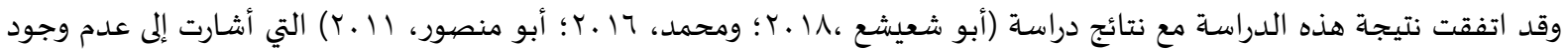

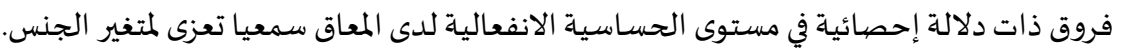

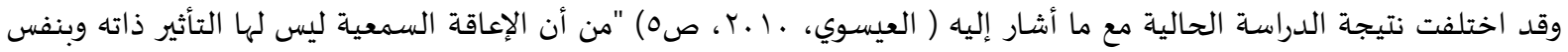

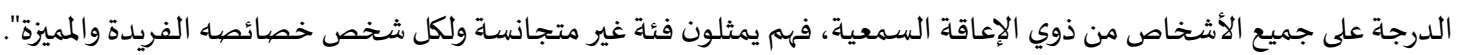

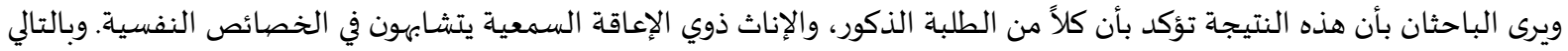

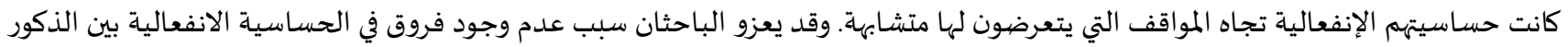

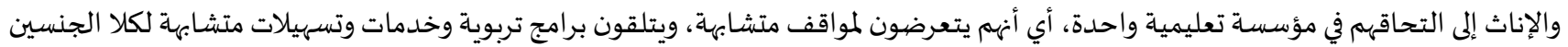

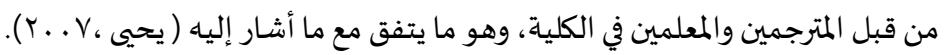

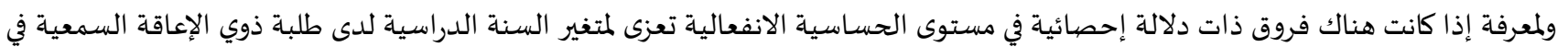

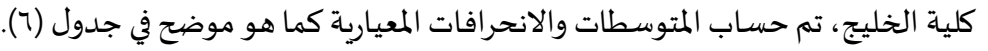
جدول (7): المتوسطات الحسابية والانحر افات المعيارية لمقياس الحساسية الانفعالية وفقا لمتغير السنة الدراسية

\begin{tabular}{|c|c|c|c|c|}
\hline الانحراف المعياري & المتوسط الحسابي & 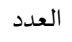 & السنة الدراسية & الشعور بالحساسية الانفعالية \\
\hline תT & 1,21 & IV & السنة الأولى & \multirow[t]{6}{*}{ الدرجة الكلية } \\
\hline.,$Y)$ & 1,77 & 19 & السنة الثانية & \\
\hline.,$T \varepsilon$ & I,VT & IV & السنة الثالثة & \\
\hline . Tr & 1,17 & v & السنة الرابعة & \\
\hline., 19 & $1, \wedge \varepsilon$ & 0 & السنه الخامسة & \\
\hline . ro & $1, V Y$ & 70 & الدرجة الكلية & \\
\hline
\end{tabular}

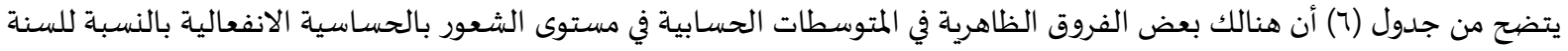

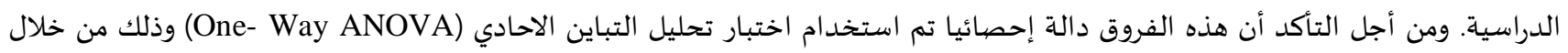

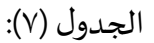

جدول (V): تحليل التباين الأحادي (One- Way ANOVA) لمستوى الشعور بالحساسية الانفعالية وفقا لمتغير السنة الدراسية

\begin{tabular}{|c|c|c|c|c|c|c|c|}
\hline |تجاه الدلالة & الدلالة & قيمة ف & متوسط المربعات & درجرجات & مجموع المربعات & مصدر التباين & الشعور بالحساسية الانفعالية \\
\hline \multirow{3}{*}{ إحيائياًا } & \multirow[t]{3}{*}{, ro } & \multirow[t]{3}{*}{$1,1+\lambda$} &.,$v 1$ & $\varepsilon$ &.,$\Gamma \wedge \varepsilon$ & بين المجموعات & \multirow[t]{3}{*}{ الدرجة الكلية } \\
\hline & & &.,$\pi T$ & 7. & $r, v \leqslant v$ & داخل المجمموعات & \\
\hline & & & - & $T \varepsilon$ & $\varepsilon, . r T$ & الدرجة الكلية & \\
\hline
\end{tabular}

$\alpha \leq 0.05$ دالة عند مستوى * 
يتضح من خلال الجدول (V) عدم وجود فروق ذات دلالة إحصائية من خلال اختبار تحليل التباين الأحادي (One- Way ANOVA) عند

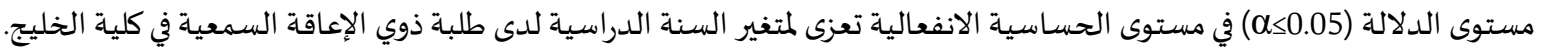

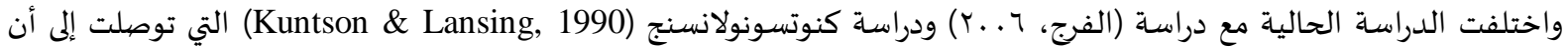

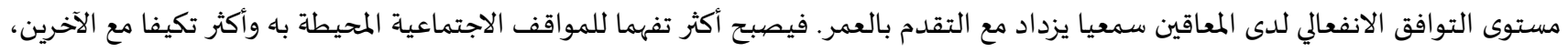

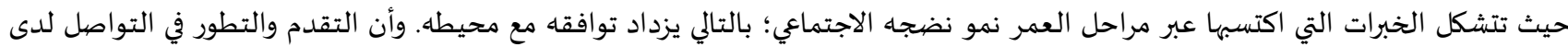

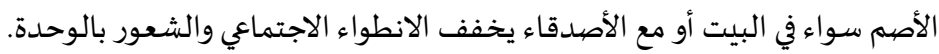

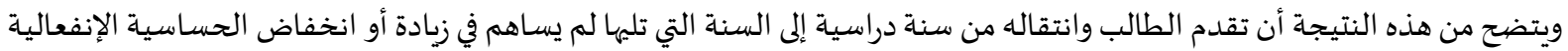

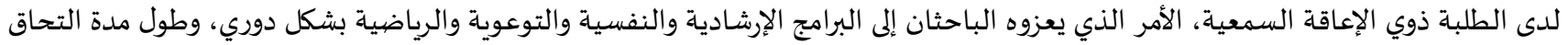

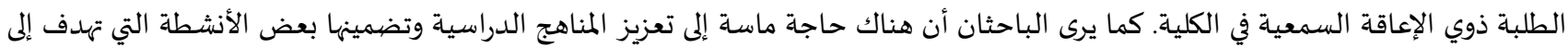

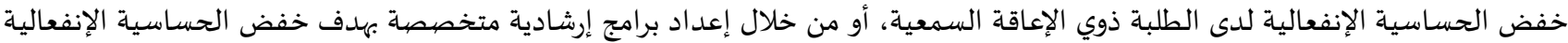

لديهم.

التوصيات:

في ضوء نتائج الدراسة الحالية، اقترح الباحثان عدة توصيات كما ياتتي:

• إعداد برامج إرشادية نفسية لخفض الحساسية الإنفعالية لدى طلبة كلية الخليج من فئة ذوي الإعاقة السمعية. تضمين المناهج الدراسية بعض الأنشطة المنهجية واللامنهجية التي تساهم في خفض الحساسية الإنفعالية لدى الطلبة ذوي الإعاقة السمعية. • اجراء دراسات أخرى تتناول مستوى الحساسية الانفعالية لدى الطلبة ذوي الإعاقة السمعية في ضوء متغيرات أخرى لم تتناولها الدراسة الحالية، كمتغير العمر، المؤسسة التعليمية، شدة الإعاقة السمعية، وغيرها من المتغيرات.

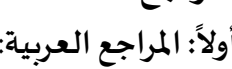

1. أبو شعيشع، دعاء السيد محمد، (Y) (Y) الحساسية الانفعالية وعلاقها بكل من السلوك التوافقي والسلوك العدواني لدى المعاقين سمعيا.

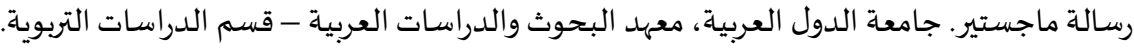
r. أبو منصور، حنان، (1) (1) الحساسية الإنفعالية وعلاقتها بالمهارات الإجتماعية لدى المعاقين سمعيا في محافظة غزة. رسالة ماجستير غير منشورة. كلية التربية، الجامعة الإسلامية - غزة.

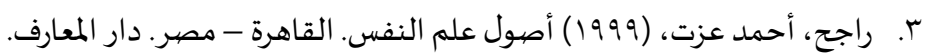
ع. رزيف، سارة؛ وخالف، كريم، (10.r) الذكاء الوجداني لدى المراهق المعاق سمعيا. رسالة ماجستير غير منشورة. كلية العلوم الإجتماعية والإنسانية- جامعة أكلي محند أولحاج- البويرة.

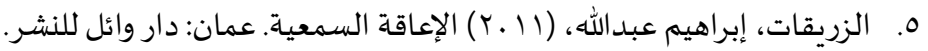

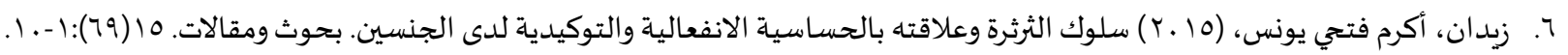

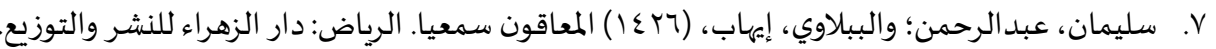

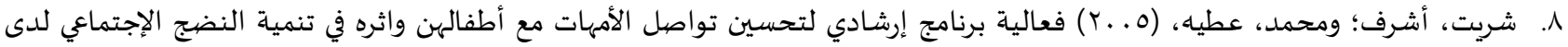

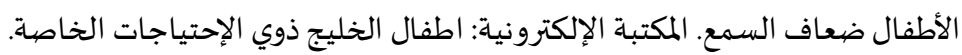

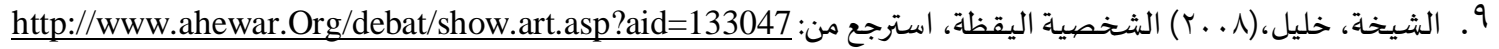

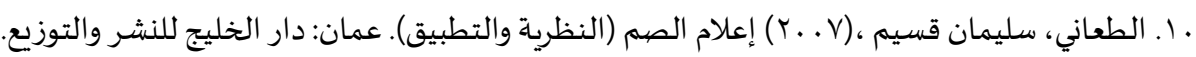

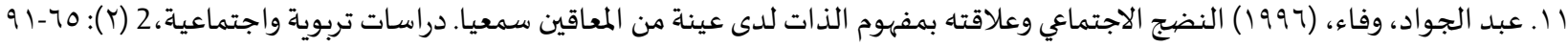

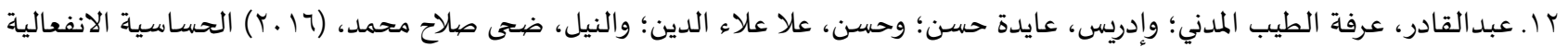
لدى التلاميذ ذوي الإعاقة السمعية وعلاقها بنوعية الحياة بمعهد الأمل لتعليم وتأهيل الصهم. بحث في علم النفس، كلية التهاية التربية، جامعة السودان. rا. عبيد، ماجدة السيد، (.1.ب) المشكلات التي تهدد أمن وسلامة الطلاب المعاقين سمعيا وبناء برنامج مقترح لتحسين فرص السلامة لهم. مجلة

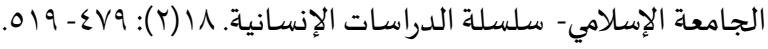




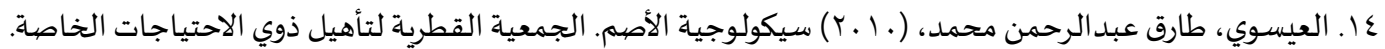

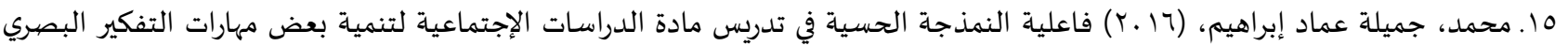
والتحصيل لدى التلاميذ المعاقين سمعيا بالمرحلة الإبتدائية. رسالة ماجستير غير منشورة، جامعة المنصورة، كلية التربية، قسم المناهج وطرق التدريس.

7 ا. الوائلي، جميلة رحيم عبد شـذر، (10 ـ أثر التعزيز التفاضلي للنقصان التدريجي في خفض الحساسية الانفعالية لدى الأطفال المعوقين سمعيا.

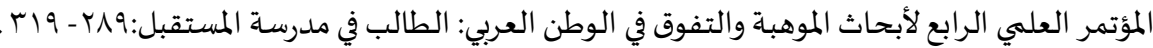

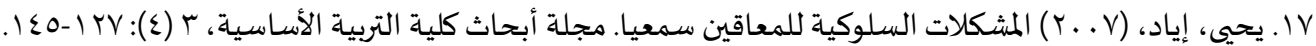

$$
\text { ثانياً: المراجع الأجنبية }
$$

[1] Bhatia. M., Dictionary of Psychology and allied Sciences, New age international, New Delhi, (2009)

[2] Lush. B., Theacher gender and verbosity in the EFL classroom, Social psychology press, (2008)

[3] Picou. E. M., Singh. G., Goy. H., Russo. F., Hickson. L., Oxenham. A. J., ... \& Launer. S., Hearing, emotion, amplification, research, and training workshop: Current understanding of hearing loss and emotion perception and priorities for future research, Trends in hearing, 22(2018), 2331216518803215, https://doi.org/10.1177/2331216518803215

[4] Pressman. L., Pipp-Siegel. S., Yoshinaga-Itano. C., \& Deas. A., Maternal sensitivity predicts language gain in preschool children who are deaf and hard of hearing, Journal of deaf studies and deaf education, 4(4)(1999), 294-304, https://doi.org/10.1093/deafed/4.4.294

[5] Rigo. T. G., \& Lieberman. D. A., Nonverbal sensitivity of normal-hearing and hearing-impaired older adults, Ear and hearing, 10(3)(1989), 184-189, https://doi.org/10.1097/00003446-198906000-00008

[6] Stevenson. J., Kreppner. J., Pimperton. H., Worsfold. S., \& Kennedy. C., Emotional and behavioural difficulties in children and adolescents with hearing impairment: A systematic review and metaanalysis, European child \& adolescent psychiatry, 24(5)(2015), 477-496, https://doi.org/10.1007/s00787015-0697-1

[7] Wallbott. H. G., \& Seithe. W., Sensitivity of persons with hearing impairment to visual emotional expression - compensation or deficit?, European journal of social psychology, 23(2)(1993), 185-193, https://doi.org/10.1002/ejsp.2420230206 


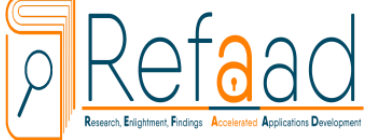

رفاد للدراسات والأبحاث

www.refaad.com
المجلة الدولية للدراسات التربوية والنفسية

e-ISSN 2520-4149 , p-ISSN 2520-4130

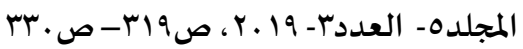

https://doi.org/DOI:10.31559/EPS2019.5.3.6

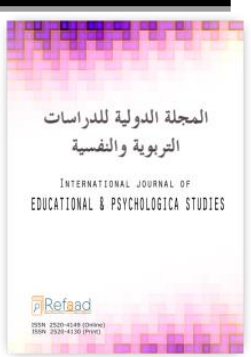

\title{
Emotional Sensitivity of Hearing Disabilities in Gulf College in the Sultanate of Oman
}

\section{Thouraia Rashid Abdullah Al Qartoubi}

Master of Counseling \& Guidnce- College of Arts \& Sciences- University of Nizwa- Oman

\author{
Ahmad M.J Alfawair \\ Assoicate Professor in Special Education- College of Arts \& Sciences- University of Nizwa- Oman \\ fawair@unizwa.edu.om
}

\begin{abstract}
This study aimed to identify the Emotional sensitivity of Hearing Impaired in Gulf College in the Sultanate of Oman. The study followed the Descriptive Approach. The study sample consist of (65) Hearing Impaired males and females students. (76.5\% of the original society), whom were selected by Purposive Sample of Hearing Impaired Students in Gulf College. The current researchers used Emotional sensitivity instrument for Abu Mansoor (2011). The researchers translated the instrument into Fingers Spelling. The study has reached the following results. The level of Emotional sensitivity was moderate (Mean $=1.72)$. The results indicated that there were no statistically significant differences at the level of $(0.05)$ in the level of Emotional sensitivity Due to gender and academic year variables. According to the study results, a set of recommendations and future studies were suggested.
\end{abstract}

Keywords: Emotional sensitivity, Deaf, Hearing Impairment, Gulf College.

\section{References:}

[1] 'bd Ạljwạd. Wfạ’, Ạlnḍj Ạlạjtmạ y W'lạqth Bmfhwm Ạldhạt Lda 'ynh Mn Ạlm ạqyn Sm yạ. Drạsạt Trbwyh Wạjtmạ yh,2(2)(1996), 65-91 .

[2] 'bdạlqạdr. 'rft Ạltyb Ạlmdny; ạdrys. 'ạydẗ Ḥsn; ḥsn. 'lạ 'lạ' Ạldyn \& ạlnyl. Ḍ̣̂y Ṣlạh Mḥmd, Ạlḥsạsyh Alạnf'ạlyh Lda Altlạmydh Dhwwy Alạ ạqh Alsm yh W'lạqthạ Bnw'yh Ạlhyạh Bm hd Ạlạml Lt'lym

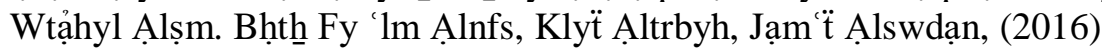

[3] 'byd. Mạjdh Ạlsyd, Ạlmsḩklạt Ạlty Thdd Ạ̉mn Wslạmẹ Ạlțlạb Ạlm'ạqyn Sm yạ Wbnạ’ Brnạmj Mqtrḥ Ltḥsyn Frṣ Ạlslạmẗ Lhm. Mjlẗ Ạljạm h Ạlạslạmy- Slslẗ Ạldrạsạt Ạlạnsạnyh, 18(2)(2010), 479- 519.

[4] Ảbw Mnṣwr. Hnạn, Ạlḥsạsyh ẠlạNf'ạlyh W'lạqthạ Bạlmhạrạt Ạlạjtmạ yh Lda Ạlm 'ạqyn Sm yạ Fy

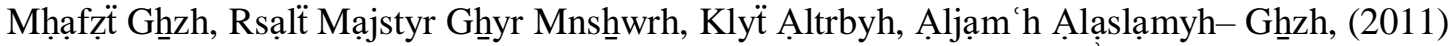

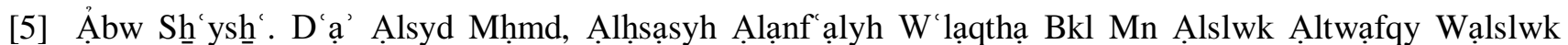

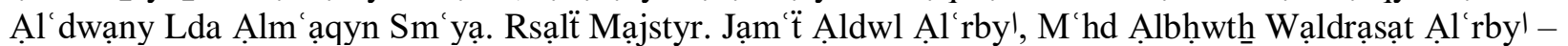
Qsm Ạldrạsạt Ạltrbwyl, (2018)

[6] Ạl'yswy. Ṭạrq 'bdạlrḥmn Mḥmd, Sykwlwjyẗ Ạlạ̉ṣm. Ạljm yh Ạlqțryh Ltạ̉hyl Dḥwy Ạlạhtyạjạt Ạlkḥạ̦h, (2010)

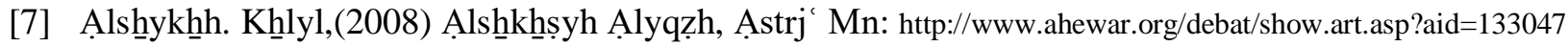


[8] Ạlț̣ạny. Slymạn Qsym, Ạ́ lạm Ạlṣm (Ạlnẓryh Wạltțbyq). 'mạn: Dạr Ạlkḥlyj Llnsḥr Wạltwzy', (2007)

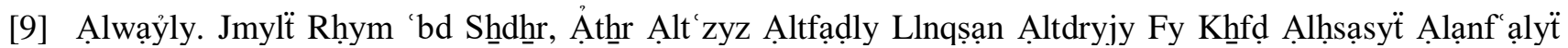
Lda Alặțạl Ạlm'wqyn Sm yạ. Ạlmw̉tmr Ạl'lmy Ạlrạb' Lạ̉bhạath Ạlmwhbë Wạltfwq Fy Ạlwṭn Ạl'rby: Ạlțạlb Fy Mdrs̈̈ Ạlmstqbl, (2015), 289- 319 .

[10] Ạlzryqạt. Ạbrạhym 'bdạllh, Ạlạ ‘ạqh Ạlsm yh, 'mạn: Dạr Wậl Llnsḥr, (2011)

[11] Bhatia. M., Dictionary of Psychology and allied Sciences, New age international, New Delhi, (2009)

[12] Lush. B., Theacher gender and verbosity in the EFL classroom, Social psychology press, (2008)

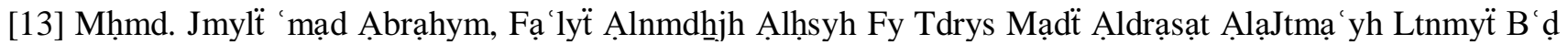
Mhạaạt Ạltfkyr Ạlbṣry Wạltḥ̣syl Lda Ạltlạmydh Ạlm ạqyn Sm yạ Bạlmrḥlh ẠlạBtdạ̉yh, Rsạlẗ Mạjstyr Ghyr Mnshwwrh, Jạm ‘̈̈ Ạlmnṣwrh, Klÿ̈ Ạltrbyh, Qsm Ạlmnạhj Wṭrq Ạltdrys, (2016)

[14] Picou. E. M., Singh. G., Goy. H., Russo. F., Hickson. L., Oxenham. A. J., ... \& Launer. S., Hearing, emotion, amplification, research, and training workshop: Current understanding of hearing loss and emotion perception and priorities for future research, Trends in hearing, 22(2018), 2331216518803215, https://doi.org/10.1177/2331216518803215

[15] Pressman. L., Pipp-Siegel. S., Yoshinaga-Itano. C., \& Deas. A., Maternal sensitivity predicts language gain in preschool children who are deaf and hard of hearing, Journal of deaf studies and deaf education, 4(4)(1999), 294-304, https://doi.org/10.1093/deafed/4.4.294

[16] Rạjḥ. Ạ̉ḥmd 'zt, Ạ̣ṣwl 'Im Ạlnfs. Ạlqạhrh - Mṣr. Dạr Ạlm ạ̣rf, (1999)

[17] Rigo. T. G., \& Lieberman. D. A., Nonverbal sensitivity of normal-hearing and hearing-impaired older adults, Ear and hearing, 10(3)(1989), 184-189, https://doi.org/10.1097/00003446-198906000-00008

[18] Rzyf. Sạrh \& khạlf. Krym, Ạldhkạa’ Ạlwjdạny Lda Almrạhq Ạlm‘ạq Sm yạa. Rsạlï Mạjstyr Ghyrr Mnshnwrh, Klyêt Ạl'lwm Ạlạitmạ yh Wạlạnsạnyh- Jạm ‘̈ Ạ̉kly Mḥnd Ạ̉wlhạj- Ạlbwyrh, (2015)

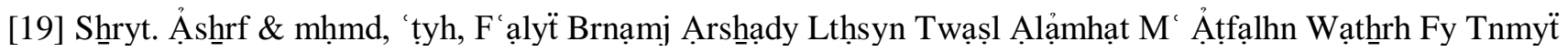
Ạlnḍj Alạjtmạ y Lda Ạlạ̉ṭạl Ḍ’ạf Ạlsm’, Ạlmktbh Ạlạiktrwnyh: Ạṭạl Ạlkhlyj Dḥwy Ạlạhtyạjạt Ạlkhạṣh, (2005)

[20] Slymạn. 'bdạlrḥmn \& ạlbblạwy.Ạyhạb, Ạlm ‘ạqwn Sm yạ. Ạlryạd: Dạr Ạlzhrạ’ Llnsḥr Wạltwzy', (1426)

[21] Stevenson. J., Kreppner. J., Pimperton. H., Worsfold. S., \& Kennedy. C., Emotional and behavioural difficulties in children and adolescents with hearing impairment: A systematic review and metaanalysis, European child \& adolescent psychiatry, 24(5)(2015), 477-496, https://doi.org/10.1007/s00787015-0697-1

[22] Wallbott. H. G., \& Seithe. W., Sensitivity of persons with hearing impairment to visual emotional expression - compensation or deficit?, European journal of social psychology, 23(2)(1993), 185-193, https://doi.org/10.1002/ejsp.2420230206

[23] Yhyyy. Ạyạd, Ạlmshnklạt Ạlslwkyh Llm’ạqyn Sm yạa. Mjlï Ạ̉bhạath Klÿ̈ Ạltrbyh Ạlạ̉sạsyh, 3(4) (2007), 127-145.

[24] Zydạn. Ạkrm Fthy Ywns, Slwk Ạltḥrtḥrh W‘lạqth Bạlḥsạsyh Ạlạnf'ạlyh Wạltwkydyh Lda Ạljnsyn. Bḥwth Wmqạạ̣t, 15(69)(2015),1-10. 